\title{
Physical organization of the 1.709 satellite IV DNA family in Bovini and Tragelaphini tribes of the Bovidae: sequence and chromosomal evolution
}

\author{
F. Adega ${ }^{\text {a }}$ R. Chaves ${ }^{\text {a }}$ H. Guedes-Pinto ${ }^{\text {a }}$ J.S. Heslop-Harrison ${ }^{b}$ \\ ${ }^{a}$ Department of Genetics and Biotechnology, Centre of Genetics and Biotechnology-CGB, University of Trás-os-Montes and Alto Douro - UTAD, \\ Vila Real (Portugal) \\ ${ }^{\mathrm{b}}$ Department of Biology, University of Leicester, Leicester (UK)
}

Abstract. Repetitive DNA in the mammalian genome is a valuable record and marker for evolution, providing information about the order and driving forces related to evolutionary events. The evolutionarily young 1.709 satellite IV DNA family is present near the centromeres of many chromosomes in the Bovidae. Here, we isolated 1.709 satellite DNA sequences from five Bovidae species belonging to Bovini: Bos taurus (BTA, cattle), Bos indicus (BIN, zebu), Bubalus bubalis (BBU, water buffalo) and Tragelaphini tribes: Taurotragus oryx (TOR, eland) and Tragelaphus euryceros (TEU, bongo). Its presence in both tribes shows the sequence predates the evolutionary separation of the two tribes (more than 10 million years ago), and primary sequence shows increasing divergence with evolutionary distance. Genome organization (Southern hybridization) and physical distribution (in situ hybridization) revealed differences in the molecular organization of these satellite DNA sequences. The data suggest that the sequences on the sex chromosomes and the autosomes evolve as relatively independent groups, with the repetitive sequences suggesting that Bovini autosomes and the Tragelaphini sex chromosomes represent the more primitive chromosome forms.
Mammalian genomes contain a high proportion of repetitive (noncoding) DNA sequences. These sequences are valuable markers of chromosomal evolution by revealing evolutionary history, chromosome structure and dynamic changes, and they provide tools for medical genetic and population genetic studies (Lander et al., 2001). The sequencing of ge-

\footnotetext{
This work was supported by the project POCTI/BIA/11285/98 and a PhD grant SFRH/BD/3280/2000 of the Science and Technology Foundation (FCT) of Portugal.

Request reprints from Raquel Chaves Department of Genetics and Biotechnology Centre of Genetics and Biotechnology-CGB University of Trás-os-Montes and Alto Douro-UTAD P-5000-911 Vila Real (Portugal) telephone: +351259350 571; fax: +351259350 572 e-mail: rchaves@utad.pt
}

nomes (among these the bovine genome) has shown the important relationship of these sequences with the function of genome components, including numerous noncoding, antisense transcripts that overlap RNAs corresponding to protein-coding genes. Closely related species share homologous satellite sequences (Waye and Willard, 1989; Jobse et al., 1995) and, by some mechanism of replacement, amplification or concerted evolution, monomers are more similar to other monomers in the same species (Nijman and Lenstra, 2001), so that the presence of shared satellite sequence variants suggests common descent (Jobse et al., 1995). Satellite DNAs can be associated with complex organizational features necessary for the function of eukaryotic genomes, such as the formation of heterochromatic genomic compartments important for proper chromosomal behavior in mitosis and meiosis (King and Cummings, 1997; Csink and Henikoff, 1998). Satellite DNAs also appear to be constituents of functional centromeres (e.g. Sun et al., 1997; Schueler et al., 2001). Repeats 

constitute a rich paleontological record, holding crucial clues about evolutionary events and driving forces (Lander et al., 2001), making it important to understand the dynamics of satellite DNA evolution (Ugarković and Plohl, 2002) and exploit the data to make inferences about phylogeny.

The bovine satellites represent approximately a quarter of the bovine nuclear DNA content (Vaiman, 1999).

The eight major different satellite DNAs recognized in the cattle genome, as early as 1978 (Macaya et al., 1978), include some that are related to each other, and certain shorter sequence motifs of these different satellite monomers are found in different tribes of the Bovidae family, and also outside the family. The 1.709 satellite IV sequence (1.709 satellite) is one of the repetitive DNA families, representing $4.3 \%$ of the bovine genome and having no resemblance to other satellite DNAs (Skowronski et al., 1984). In the domestic cow, this satellite is organized as $3.8-\mathrm{kb}$ tandem arrays where the monomers are mosaic in structure (Skowronski et al., 1984). When Modi et al. (1996, 2004) analyzed the 1.709 satellite DNA family in the artiodactyls they surveyed, they only observed its existence in members of the Bovini tribe, finding that several fragments are common among many Bovini species, indicating the existence of conserved and homogenized arrays. Therefore, this satellite family was classified as an evolutionarily young repeat, originating following the divergence of the Boselaphini, but prior to the Bovini diversification, about 5 million years ago (Jobse et al., 1995; Modi et al., 1996, 2004).

Here we have made a detailed analysis of 1.709 satellite DNA sequences from five Bovidae species belonging to Bovini: Bos taurus (BTA, cattle), Bos indicus (BIN, zebu), Bubalus bubalis (BBU, water buffalo) and Tragelaphini tribes: Taurotragus oryx (TOR, eland) and Tragelaphus euryceros (TEU, bongo). In contrast to previous work (Jobse et al., 1995; Modi et al., 1996, 2004), we found this satellite DNA family in another tribe (Tragelaphini) besides Bovini. These findings and the differences at the molecular organization level among these five satellite DNA sequences, each representative of the five species genomes analyzed, allowed greater resolution of the phylogenetic history of this satellite DNA family and hence the phylogeny of the species.

\section{Materials and methods}

DNA extraction, amplification and sequencing

Genomic DNA from the species analyzed: Bos taurus (BTA, cattle), Bos indicus (BIN, zebu), Bubalus bubalis (BBU, water buffalo), Taurotragus oryx (TOR, eland) and Tragelaphus euryceros (TEU, bongo) was isolated from peripheral blood using standard methods (Montgomery and Sise, 1990).

PCR specific primers for the 1.709 satellite DNA sequence from cattle were designed following Nijman and Lenstra (2001): 5 -AAGCTTGTGACAGATAGAACGAT-3 and 5-CAAGCTGTCTAGAATTCAGGGA-3 which would amplify the region from the first base to bp 603 (including primers) of sequences X00979. Amplification of genomic DNA (Chaves et al., 2003) gave fragments from each of the species; PCR products were cloned into a pCR 4-TOPO plasmid (Invitrogen, Life Technologies) and 25 clones were sequenced from the five species. Each species clone was named by species of origin [BTA1.709 (B. taurus), BIN1.709 (B. indicus), BBU1.709 (B. bubalis), TOR1.709 (T. oryx) and
TEU1.709 (T. euryceros)] and used as probe for Southern blot and FISH experiments.

DNA sequences were analyzed using BLASTN searches of the GenBank and EMBL databases and CLUSTALW for alignment. Sequence data from the BTA1.709 clone was deposited under accession number AF446392 (EMBL Nucleotide Sequence Database).

Southern and in situ hybridization

Genomic DNA was digested with the restriction endonucleases Bam$\mathrm{HI}$ and EcoRI, size separated in $0.8 \%$ agarose gels in 1 ! TBE buffer for $8 \mathrm{~h}$ and transferred to Hybond $\mathrm{N}+$ (Amersham Biosciences) membranes. The membranes were probed with each of the clones (BTA1.709, IN1.709, BBU1.709, TOR1.709 and TEU1.709) using $100 \mathrm{ng}$ of probe and the ECL-direct (Amersham) hybridization system. Hybridization was carried out in $6 \mathrm{M}$ urea at $42^{\circ} \mathrm{C}$ and the most stringent post hybridization wash was in 0.2 ! SSC at $42^{\circ} \mathrm{C}$, allowing sequences with more than $86 \%$ similarity to remain hybridized.

Chromosome preparations of each of the species analyzed were made from short term lymphocyte cultures of whole blood samples using standard protocols (Chaves et al., 2002). The karyotypes of species from the Bovini tribe were organized according to recommendations from the ISCNDB (2000). Briefly, B. taurus and B. indicus have a similar karyotype $(2 \mathrm{n}=60$, with 29 acrocentric autosome pairs, and submetacentric sex chromosomes $\mathrm{X}$ and $\mathrm{Y}) ; B$. bubalis $(2 \mathrm{n}=50$, with 19 acrocentric and five meta- or submetacentric autosome pairs, and the sex chromosomes are an acrocentric $\mathrm{X}$ and a small submetacentric $\mathrm{Y}$ ). The karyotypes of the Tragelaphini species (females) were organized according to Gallagher and Womack (1992): T. oryx and T. euryceros, $(2 \mathrm{n}=32,13$ autosomal chromosome pairs are meta- or submetacentric, a fourteenth pair is acrocentric, the $\mathrm{X}_{2}$ acrocentric chromosome, thought to be homologous to cattle 13, and the acrocentric sex chromosome $\mathrm{X}_{1}$; Gallagher and Womack, 1992). The subspecies of T. euryceros used in the present work has one additional acrocentric autosome pair; the karyotypes of the Tragelaphini females used are $2 n=32, X_{1} X_{1} X_{2} X_{2}$ for TOR and $2 n=34$, $\mathrm{X}_{1} \mathrm{X}_{1} \mathrm{X}_{2} \mathrm{X}_{2}$ for TEU.

Air dried slides were treated at $65^{\circ} \mathrm{C}$ for $6 \mathrm{~h}$ and then submitted to in situ restriction endonuclease digestion with ApaI and fixed with paraformaldehyde as described by Chaves et al. (2002). Slides were stained with DAPI (the inversion of the DAPI color enhanced the RE-banding helpful for chromosome identification) and then used for in situ hybridization experiments.

Metaphases were hybridized in situ with the 1.709 satellite clones labeled with biotin-16-dUTP (Sigma) or digoxigenin-11-dUTP (Roche) by PCR using standard methods (Schwarzacher and Heslop-Harrison, 2000; Chaves et al., 2003). Hybridization was carried out in 2 ! SSC and $50 \%$ formamide at $37^{\circ} \mathrm{C}$ overnight, and the most stringent post-hybridization wash was in 0.2 ! SSC at $42^{\circ} \mathrm{C}$, allowing sequences with more than $82 \%$ similarity to remain hybridized

Biotin-labeled probes were detected with avidin conjugated to fluorescein isothiocyanate (FITC) (Vector Laboratories), and digoxigeninlabeled probes with anti-digoxigenin (Roche) conjugated to 5-carboxytetramethylrhodamine (5-TAMRA). Chromosomes were counterstained with DAPI and mounted in Vectashield (Vector Laboratories).

Chromosome preparations were analyzed with a Zeiss Axioplan 2 Imaging microscope coupled to an Axiocam digital camera and with the AxioVision software (version 3.1). Digitized photos were prepared for printing in Adobe Photoshop (version 5.0); contrast, overlaying and color optimization functions were used and all affected the whole of the image equally.

\section{Results}

\subsection{9 satellite DNA sequences in Bovinae}

Amplification of genomic DNA with primers for the Bos taurus 1.709 satellite DNA family in species from the Bovini and Tragelaphini tribes gave PCR fragments with lengths of approximately $600 \mathrm{bp}$ in B. taurus, B. indicus, B. bubalis and 
T. oryx, and $630 \mathrm{bp}$ in T. euryceros, and one fragment from each was cloned. In a few cases where more than one fragment was amplified, the 600-bp fragment was selected for reamplification and cloning. All clones were homologous to the 1.709 satellite IV DNA sequence (EMBL accession X00979) and were about $60 \%$ AT content. TEU1.709 was 629 bp long, while other clones were 601 to $603 \mathrm{bp}$ long, showing between $78 \%$ and $98 \%$ similarity between each other (see dotplots in Fig. 1 and phylogenetic tree in Fig. 5), and the reference 1.709 sequence X00979. TEU1.709 exhibited insertions (a total of $49 \mathrm{bp}$, largely as internal duplications around bp 100) and deletions (23 bp), seen as parallel lines, discontinuities and diagonal shifts in Fig.1d).

\section{Molecular and genomic organization of 1.709 satellite DNA family}

As anticipated from the similarities found from the sequence analysis, all 1.709 satellite DNA clones hybridized to the sequences from the five species tested, and restriction enzyme analysis showed characteristic organization in different genera (data not shown). The 1.709 satellite DNA hybridization patterns differed between the Bovini and Tragelaphini tribes; and within the Bovini tribe, between the species $B$. taurus/B. indicus (which were indistinguishable) and $B$. bubalis. The satellite sequences occur in larger (multi-megabasesized) structures (as shown by, e.g., in situ hybridization, see below) made up of the $3.8-\mathrm{kb}$ monomeric unit or two or more units where internal sites are present. The restriction fragment length polymorphisms with different hybridization patterns showed tribe-specific differences both in the longrange organization and in the restriction sites present within 1.709 satellite repeat units.

\section{Cross-species analysis of 1.709 satellite DNA}

In situ hybridization was used to analyze the chromosomal distribution of the satellite DNA family from all the species (clones: BTA1.709, BIN1.709, BBU1.709, TOR1.709 and TEU1.709). The satellite showed a prominent centromeric localization in each of the tribes analyzed, and there was sufficient homology that the 1.709 satellite probes cross-hybridized between all species analyzed (Fig. 3), in accordance with the results from Southern hybridization.

Figure 2a-f shows in situ hybridizations of Bovini 1.709 satellite DNA to Bovini species chromosome preparations. In the B. bubalis (Fig. 2a, b), the probes BBU1.709 (Fig. 2a), BIN1.709 (Fig. 2b) and BTA1.709 (data not shown), revealed hybridization signals on all acrocentric autosomes, in two pairs of meta/submetacentric autosomes (e.g. Fig. 2a, arrow) and in the sex chromosome $\mathrm{X}$. The centromeric in situ hybridization was heterogeneous when comparing different autosomes. It is also notable that strong signal hybridization was observed in the $\mathrm{X}$ chromosome pericentromeric region. In $B$. indicus (Fig. 2c, d), the 1.709 probes from B. bubalis (Fig. 2c), B. indicus (Fig. 2d) and B. taurus (data not shown) hybridized heterogeneously to most but not all of the autosomal chromosomes. No signal was detected in the sex chromosomes (X or Y). In B. taurus (Fig. 2e, f), the 1.709 probes from B. bubalis
(Fig. 2e), B. indicus (Fig. 2f) and B. taurus (data not shown) also hybridized (as in $B$. bubalis and $B$. indicus chromosomes) heterogeneously to autosomal chromosomes; again, no signal from the 1.709 satellite DNA was detected on the sex chromosomes.

Figure $2 \mathrm{~g}, \mathrm{~h}$ presents representative in situ hybridizations of Tragelaphini 1.709 satellite DNA to Tragelaphini chromosome preparations. In $T$. oryx chromosomes it was possible to observe faint hybridization signals in some autosome pairs, although the acrocentric chromosomes $\mathrm{X}_{2}$ and the sex chromosome $\mathrm{X}_{1}$ show the most pronounced signal (Fig. $2 \mathrm{~g}$ ). In $T$. euryceros metaphases, hybridization was only observed on the $\mathrm{X}_{1}$ and $\mathrm{X}_{2}$ chromosomes (Fig. 2h).

Some 1.709 satellite DNA polymorphisms were observed between homologous chromosomes in the Bovini species analyzed; BBU polymorphisms were less than those in BIN and BTA.

Cross-Tribe physical analysis of 1.709 satellite DNA

Figure $3 \mathrm{a}-\mathrm{f}$ shows the FISH results of the cross-tribe hybridization of 1.709 satellite DNA between Bovini and Tragelaphini species. In B. bubalis and B. taurus, hybridization with TOR1.709 (Fig. 3a, c) and TEU1.709 (Fig. 3b, d) revealed similar in situ hybridization patterns with those with the Bovini 1.709 satellite DNA, and there were no notable differences between the 1.709 probes analyzed in B. bubalis chromosomes, B. taurus or B. indicus (data not shown). As with homologous probes (1.709 B. taurus and B. indicus, not shown), prominent labeling was detected at the distal region of the $B$. bubalis $\mathrm{X}$ chromosome centromere.

In the hybridization of Bovini 1.709 (shown for the BBU sequence, Fig. 3e, f) to the Tragelaphini species in analysis, we observed some differences from the intra-tribe hybridizations. T. oryx (Fig. 3e) showed extended labeling in almost all autosomal chromosomes, besides the sex $\mathrm{X}_{1}$, and these hybridization signals were more pronounced than was observed with Tragelaphini probes; in T. oryx (Fig. 3f), the BBU1.709 satellite was present in the majority of the autosomal chromosomes, as well as the sex chromosomes.

We co-hybridized two 1.709 probes representative of the tribes Bovini and Tragelaphini to chromosomes of the species analyzed. In Fig. 4, the BBU1.709 and TOR1.709 probes localize to the centromeres of all chromosomes. Most chromosomes have the BBU variant, some have both variants nearly collocalized, while a few show the two sequences adjacent to each other (Fig. 4e).

\section{Discussion}

The analysis of satellite DNA sequences, organization and chromosome distribution is a valuable tool for measuring species phylogenetic relationships, while also elucidating important aspects of evolution of both genome and repetitive sequences (Chaves et al., 2000; Lander et al., 2001; Ugarkovićand Plohl, 2002).

The DNA sequence analysis demonstrated that the 1.709 
satellite DNA sequences from Bovini species have a higher degree of homology (93\%-99\%), than the ones from Tragelaphini species $(81 \%$, although distorted by the internal repetition and deletions, Fig. 1). The 1.709 satellite DNA family has not been reported from the Tragelaphini species. Modi and collaborators $(1996,2004)$ analyzed, by Southern and in situ hybridization, several Artiodactyls (including Tragelaphini species) with various Bos taurus satellite DNA families including the 1.709 satellite DNA concluding that the 1.709 satellite DNA was not present in the Tragelaphini species due to the absence of hybridization in these species (DNA and chromosomes). In Figs. 2 and 3, we demonstrate that there is hybridization of Bovinae 1.709 satellite DNA on Tragelaphini chromosomes and isolated DNA. This apparent contradiction in our results and the results from Modi et al. (1996, 2004) could perhaps be explained by different isolated variants of 1.709 satellite DNA and/or different hybridization stringencies in both studies. The primers used in their work are internal to those we used (bp 33 to 569) which could result in the amplification of different variants of the 1.709 satellite DNA family. Nevertheless, our sequences and hybridizations of the 1.709 satellite DNA from Bovini and Tragelaphini (Fig. 1) indicate the presence of the same satellite family with only limited divergence between the tribes, so the sequence originated before divergence of Bovini and Tragelaphini tribes (something like 10 million years). Modi et al. (1996, 2004) did not find this DNA sequence satellite family in Boselaphini, but it would be interesting to identify any related sequences from this tribe.

A phylogeny of the 1.709 satellite DNA sequences from the five Bovini and Tragelaphini species studied in the present work is shown in the neighbour joining tree (Fig. 5), including also the sequence of Skowronski et al. (1984). The phylogenetic tree is consistent with the hybridizations to genomic DNA digests (data not shown) and to chromosomes (Figs. 2 and 3). The chromosomal distribution pattern is particularly informative in showing the changes that occurred during and since the separation of the tribes from a common ancestor: the 1.709 DNA family from either Bovini or Tragelaphini tribes showed similar hybridization to Bovini chromosomes (Fig. 2a-f and Fig. 3a-d), while the Tragelaphini 1.709 DNA family showed strong labeling only on $\mathrm{X}_{1}$ and $\mathrm{X}_{2}$ chromosomes; the Bovini sequence also labeled autosomes. It was notable that the heterologous Bovini 1.709 gave a strong signal on TOR chromosomes; the related BBU and TOR satellite IV probes show about $78 \%$ sequence similarity and the locations of variants more related to each other were clearly distinguishable by in situ hybridization at a higher stringency (stringent wash in 2 ! SSC, $50 \%$ formamide at $42^{\circ} \mathrm{C}$ ) (Fig. 4). Thus, we suggest that the Bovini and Tragelaphini 1.709 satellite DNA families are 1.709 sequence variants which can both be present and can both amplify and homogenize on different segments of the satellite blocks. This would explain the different hybridizations observed with the probes on TOR chromosomes (Figs. 2-4). This conclusion is also supported by similar findings of Modi and co-authors (2004), who described higher order repeats (HORs, by PFGE) of different sizes existing within a genome. They also concluded that as this satellite family is dispersed to multiple chromosomes in the bovid species analyzed, it is possible that different HORs are localized on different chromosomes (Modi et al., 2004). Our results and those of Modi et al. (2004) support the feedback model for the evolution of Bovini satellite DNA repeats (Nijman and Lenstra, 2001). The fluctuations in the relative amounts of the sequence variants of 1.709 satellite DNA support a second phase of that model, characterized by initial mutations during which interactions are mainly between monomers of identical sequence, and sequence variants amplify and contract independently.

The model of concerted evolution of sequences fits our data on the 1.709 satellite DNA family, comparing Bovini and Tragelaphini species (Fig. 5). In Tragelaphini species, the 1.709 satellite DNA is nearly chromosome-specific (being confined to $\mathrm{X}_{1}$ and $\mathrm{X}_{2}$ chromosomes, Fig. $2 \mathrm{~g}, \mathrm{~h}$ ), and $B$. bubalis species have more of the 1.709 satellite DNA in the $\mathrm{X}$ chromosome (Fig. 2a, b). The satellite family is not abundant in the other Bovidae X chromosomes (Fig. 2c-f). We cannot rule out evolutionarily recent transposition of autosomal 1.709 sequences to the $\mathrm{X}$ chromosome, but sequence distribution suggests that the evolutionary pathways of the autosomal and sex chromosomes may be independent. Thus we suggest divergence and homogenization of the sequence variants from a common ancestor into the Bovini and Tragelaphini tribes, while there are abundant, sex-chromosome specific, variants amplified in the Tragelaphini species.

Domestic cattle and other Bovinae species with 58 acrocentric autosomes, $\mathrm{X}$ and $\mathrm{Y}(2 \mathrm{n}=60)$ are thought to retain the ancestral autosomal complement, although the ancestral conditions of the Bovidae $\mathrm{X}$ and $\mathrm{Y}$ chromosomes remain to be determined (Gallagher et al., 1994, 1999; Chaves et al., 2005). The Bovidae $X$ chromosome shows considerable variation (in contrast to the autosomal conservatism), mostly a consequence of the variation in amount and position of heterochromatin and satellite DNA sequences (Chaves et al., 2005). Our results with the 1.709 satellite DNA family in Bovini and Tragelaphini species reveal that the autosomes and sex chromosomes can behave as independent groups in evolutionary terms, as has been considered for chromosomal evolution and heterochromatin (Robinson, 1998; Gallagher et al., 1999; Chaves et al., 2004). Moreover, satellite DNA families that are simultaneously found in autosomal and sex chromosomes (and particularly the X), are suggestive of a primitive form of this sex chromosome (Gallagher et al., 1999; Chaves et al., 2005). The present results, based on the repetitive sequences, suggest that the primitive chromosome forms are the $\mathrm{X}$ chromosomes from Tragelaphini and water buffalo (Bovini), and the Bovini autosomal complement. It is not clear whether the satellite sequences are continuing to evolve or whether there are bursts of evolution followed by periods of relative stability (Chaves et al., 2000); whichever, genome rearrangements associated with chromosome reshaping during evolution will lead to reproductive isolation. 


\section{References}

Chaves R, Guedes-Pinto H, Heslop-Harrison JS, Schwarzacher T: The species and chromosomal distribution of the centromeric -satellite I se-quence from sheep in the tribe Caprini and other Bovidae. Cytogenet Cell Genet 91: 62-66 (2000).

Chaves R, Adega F, Santos S, Heslop-Harrison JS, Guedes-Pinto H: In situ hybridization and chro- mosome banding in mammalian species. Cyto- genet Genome Res 96:113-116 (2002).

Chaves R, Adega F, Heslop-Harrison JS, Wienberg J, Guedes-Pinto H: Complex satellite DNA reshuffling in the polymorphic $t(1 ; 29)$ Robertsonian translocation and evolutionary derived chromo- somes in cattle. Chromosome Res 11:641-648 (2003).

Chaves R, Santos S, Guedes-Pinto H: Comparative analysis (Hippotragini versus Caprini, Bovidae) of X-chromosome's constitutive heterochroma- tin by in situ restriction endonuclease digestion: X-chromosome constitutive heterochromatin evolution. Genetica 121: 315-325 (2004)

Chaves R, Guedes-Pinto H, Heslop-Harrison JS Phylogenetic relationships and the primitive $X$ chromosome inferred from chromosomal and satellite DNA analysis in Bovidae. Proc R Soc London B 272:2009-2016 (2005).

Csink AK, Henikoff S: Something from nothing: the evolution and utility of satellite repeats. Trends Genet 14:200-204 (1998).

Gallagher DS, Womack JE: Chromosome conservation in the Bovidae. J Hered 82:287-298 (1992).

Gallagher DS, Derr JN, Womack JE: Chromosome conservation among the advanced pecorans and determination of the primitive bovid karyotype. J Hered 85:204-210 (1994).

Gallagher DS, Davis SK, De Donato M, Burzlaff JD, Womack JE, Taylor JF, Kumamoto AT: A molecular cytogenetic analysis of the tribe Bovini (Artiodactyla: Bovidae: Bovinae) with an emphasis on sex chromosome morphology and NOR distribution. Chromosome Res 7: 481-492 (1999).

ISCNDB (2000) International System for Chromo- some Nomenclature of Domestic Bovids, Di Be- rardino D, Di Meo GP, Gallagher DS, Hayes H, Iannuzzi L (coordinator) (eds). Cytogenet Cell Genet 92:283-299(2001).

Jobse C, Buntjer JB, Haagsma N, Breukelman HJ, Beintema JJ, Lenstra JA: Evolution and recom- bination of bovine DNA repeats. J Mol Evol 41: 277-283 (1995)

King LM, Cummings MP: Satellite DNA repeat sequence variation is low in three species of burying beetles in the genus Nicrophorus (Coleoptera: Sil- phidae). Mol Biol Evol 14:1088-1095 (1997).

Lander ES, Linton LM, Birren B, Nusbaum C, Zody $\mathrm{MC}$, Baldwin J, et al: Initial sequencing and analysis of the human genome. Nature 409:860-921 (2001).

Macaya G, Cortadas J, Bernardi G: An analysis of the bovine genome by density-gradient centrifuga- tion. Preparation of the dG + dC-rich DNA com- ponents. Eur J Biochem 84:179-188 (1978).

Modi WS, Gallagher DS, Womack JE: Evolutionary histories of highly repeated DNA families among the Artiodactyla (Mammalia). J Mol Evol 42: 337-349 (1996)
Modi WS, Ivanov S, Gallagher DS: Concerted evolution and higher-order repeat structure of the 1.709 (Satellite IV) family in Bovids. J Mol Evol 58:460-465 (2004)

Montgomery GW, Sise JÁ: Extraction of DNA from sheep white blood cells. New Zeal J Agr Res 33: 437-441 (1990).

Nijman IJ, Lenstra JA: Mutation and recombination in cattle satellite DNA: a feedback model for the evolution of satellite DNA repeats. J Mol Evol 52:361-371 (2001)

Robinson TJ, Harrison WR, Ponce de León A, Davis SK, Elder FFB: A molecular cytogenetic analysis of $\mathrm{X}$ chromosome repatterning in the Bovidae: transpositions, inversions, and phylogenetic inference. Cytogenet Cell Genet 80: 179-184 (1998)

Schueler MG, Higgins AW, Rudd MK, Gustashaw K, Willard HF: Genomic and genetic definition of a functional human centromere. Science 294:109- 115 (2001).

Schwarzacher T, Heslop-Harrison P: Practical in situ Hybridization (Bios, Oxford 2000).

Skowronski J, Plucienniczak A, Badnarek A, Jawor- ski J: Bovine 1.709 satellite Recombination hot- spots and dispersed repeated sequences. J Mol Biol 177:399-416 (1984)

Sun X, Wahlstrom J, Karpen G: Molecular structure of a functional Drosophila centromere. Cell 91: 1007-1019 (1997)

Ugarković D, Plohl M: Variation in satellite DNA profiles - causes and effects. EMBO J 21:5955- 5959 (2002)

Vaiman D: The molecular genetics of cattle, in Fries R, Ruvinski A (eds): Genetics of Cattle (CAB, Cambridge 1999).

Waye JS, Willard HF: Concerted evolution of alpha satellite DNA: Evidence for species specificity and a general lack of sequence conservation among alphoid sequences of higher primates. Chromosoma 98:273-279 (1989) 


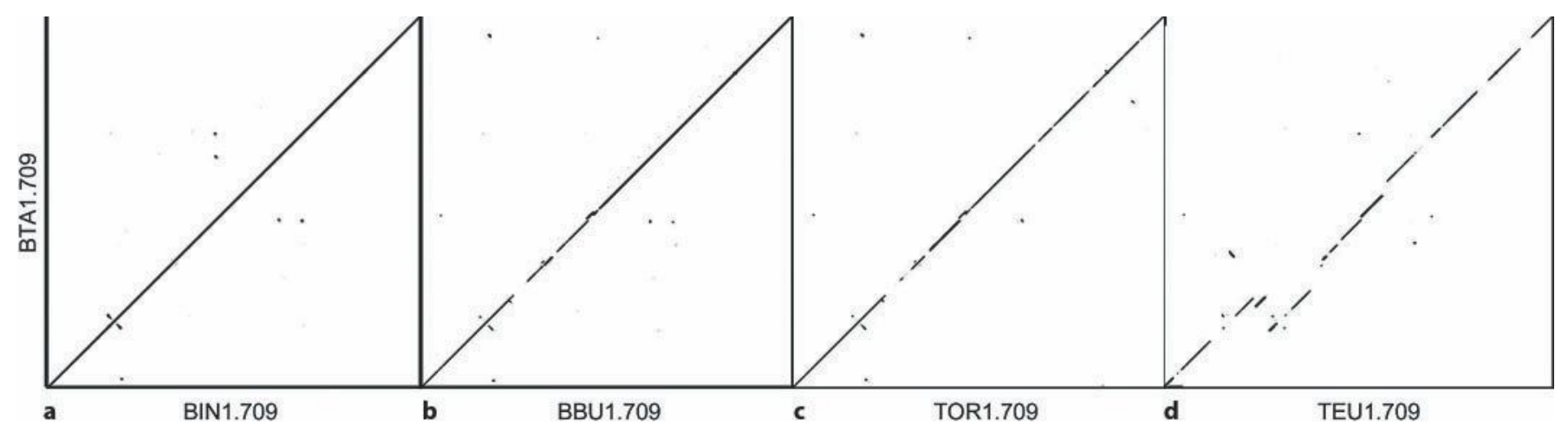

Fig. 1. A dotplot comparing 1.709 satellite DNA sequence fragments from cattle (Bos taurus, BTA, Y axis) with (X axis): (a) Zebu (Bos indicus, BIN) with minimal divergence; (b) Water buffalo (Bubalus bubalis, BBU) with some diver- gence; (c) Eland (Taurotragus oryx, TOR) with about $85 \%$ homology to BTA; and (d) Bongo (Tragelaphus euryceros, TEU) with short regions of duplication (parallel lines) and deletions (horizontal gaps). A sliding window of 10 nucleotides was used with a dot being placed when eight or more were identical. 

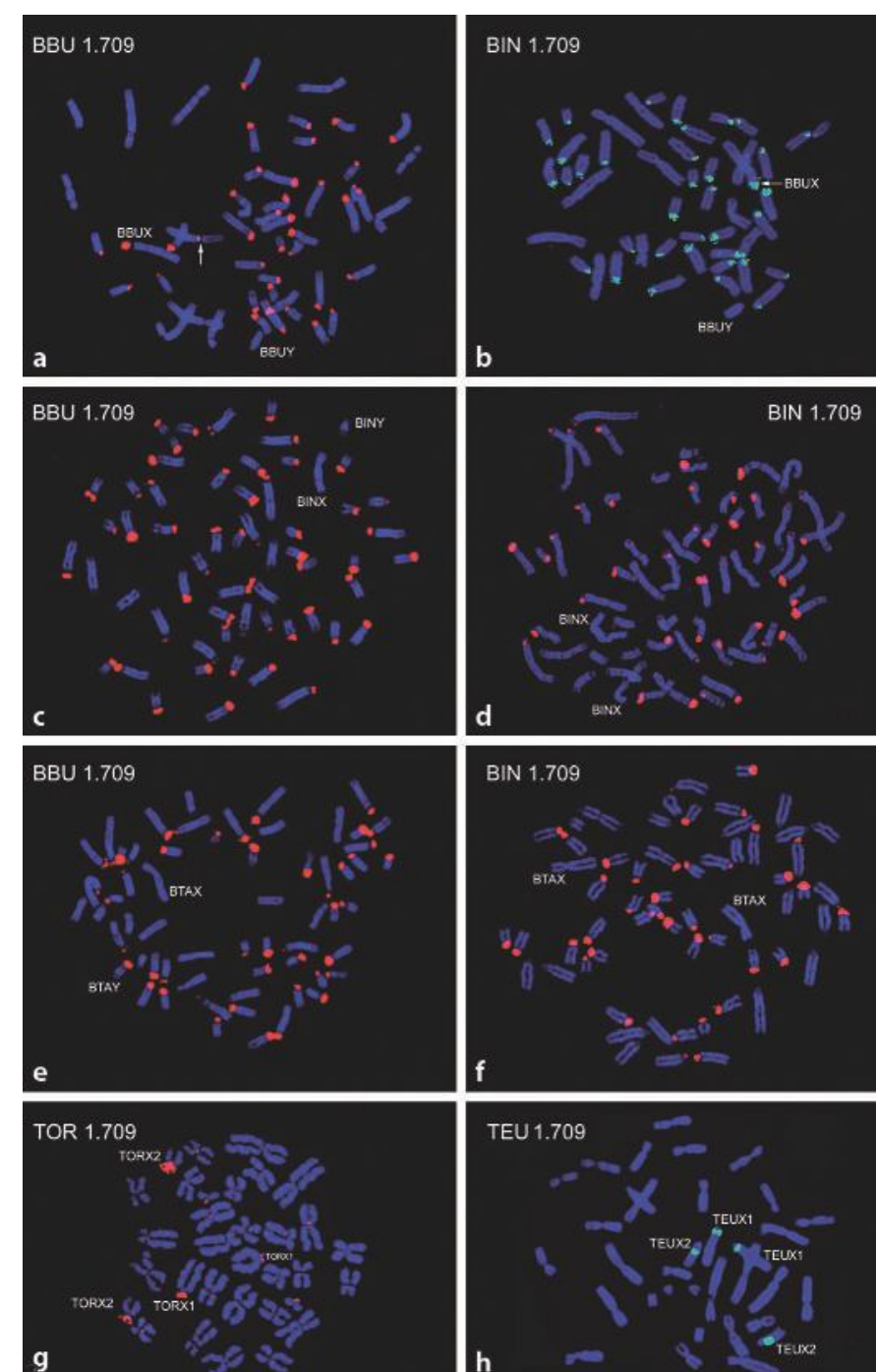

d

BIN 1.709
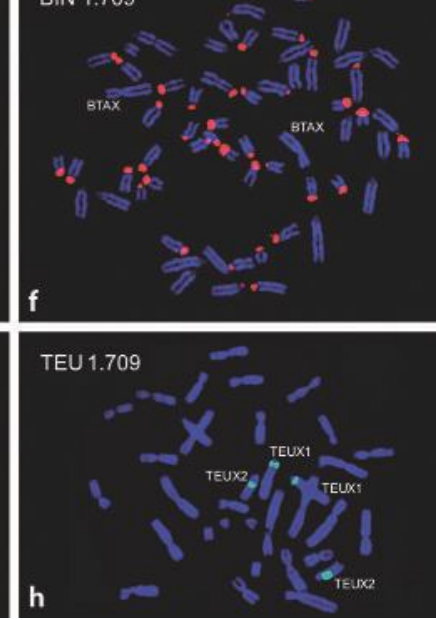

Fig. 2. Chromosomes from Bovini (a-f) and Tragelaphini $(g, h)$ showing in situ hybridization of 1.709 satellite DNA from the same tribe. (a, b) Hybridization of BBU1.709 and BIN1.709 on B. bubalis; (c, d) hybridization of BBU1.709 and BIN1.709 on B. indicus; (e, f) hybridization of BBU1.709 and BIN1.709 on B. taurus and (g, h) hybridization of TOR1.709 on $T$. oryx and TEU1.709 on T. euryceros. The sex chromosomes are indicated in each metaphase along with, in the Tragelaphini species, the autosomal pair $\mathrm{X}_{2}$.

Fig. 3. In situ hybridization of Tragelaphini 1.709 satellite DNA to chromosomes from Bovini species (a-d), and Bovini 1.709 satellite DNA to Tragelaphini species (e, f). (a, b) Hybridization of TOR1.709 (a) and TEU1.709 (b), respectively on B. bubalis; (c, d) hybridization of TOR1.709 and TEU1.709, respectively, on B. taurus; (e, f) hybridization of BBU1.709 on T. oryx and T. euryceros, respectively. The sex chromosomes are indicated in each metaphase, and in the case of Tragelaphini species, the sex chromosomes are identified as well as the autosomal pair $\mathrm{X}_{2}$.

Fig. 4. In situ hybridization of TOR1.709 (red) (c) and BBU1.709 (green) (d) satellite DNA to a metaphase of water buffalo, BBU. (a) Overlay of the two in situ hybridization signals in BBU chromosomes. (b) In situ hybridization signals. (e) Enlarged chromosomes showing chromosomes with only the BBU signal, with collocalization of the TOR and BBU signals, and with the TOR signal being distal to the BBU signal.
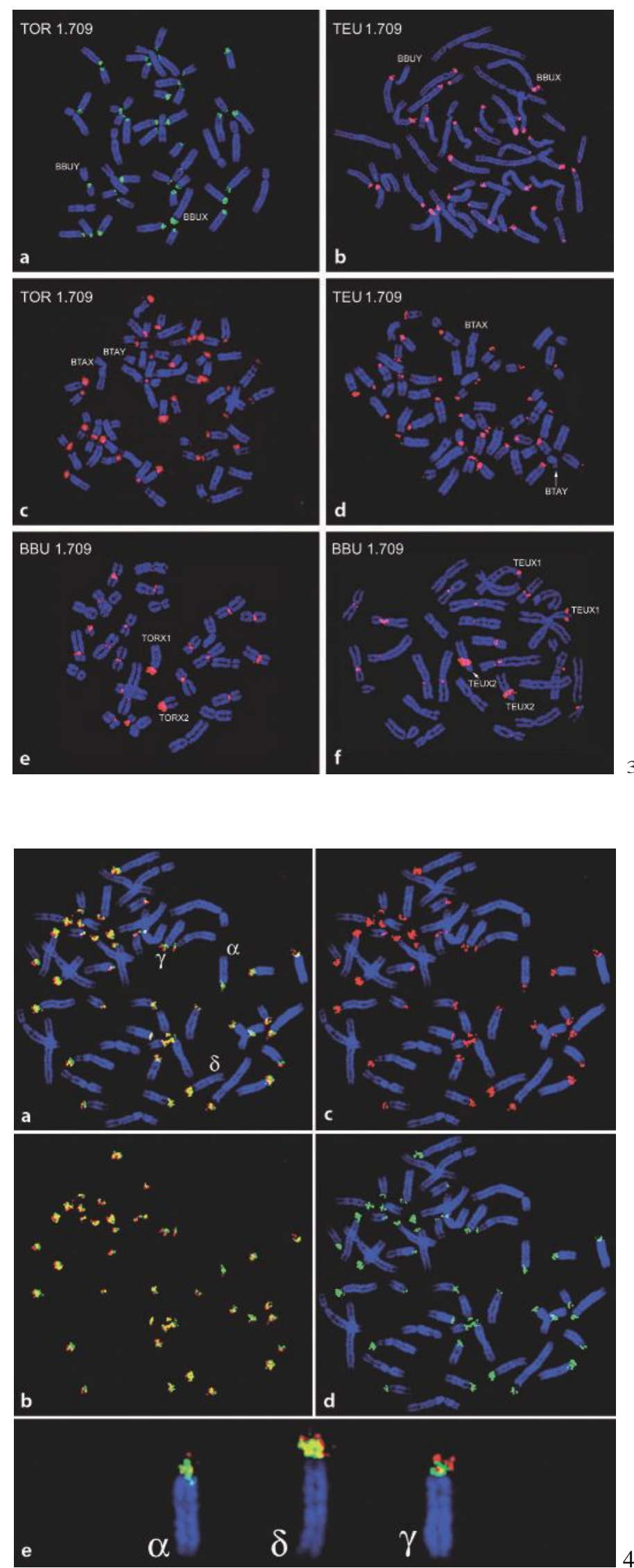


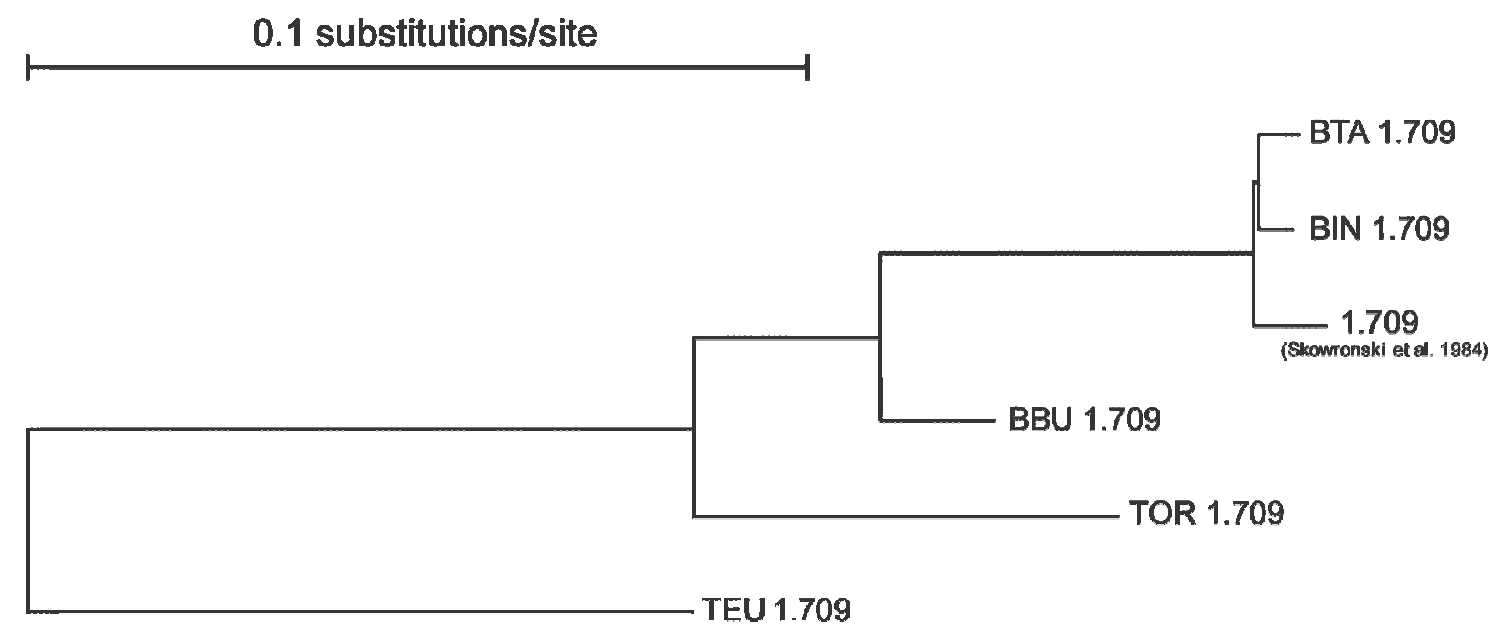

Fig. 5. Jukes and Cantor distance (indels are considered) between 1.709 satellite sequences studied here. The neighbour joining tree (with TEU1.709 as outgroup) shows bootstrap values above 60. 